\title{
A suspected case of autoinduction of voriconazole metabolism in a patient with cerebral aspergillosis
}

This article was published in the following Dove Press journal:

Drug, Healthcare and Patient Safety

8 September 2017

Number of times this article has been viewed

\author{
Martin J Ferguson' \\ Maria L Randles ${ }^{2}$ \\ Declan G de Freitas ${ }^{3}$ \\ 'Pharmacy Department, Beaumont \\ Hospital, Beaumont, Dublin, 2Pharmacy \\ Department, Wexford General \\ Hospital, Wexford, ${ }^{3}$ Department \\ of Transplantation, Urology and \\ Nephrology, Beaumont Hospital \\ Kidney Centre, Dublin, Ireland
}

Correspondence: Martin J Ferguson Pharmacy Department, Beaumont Hospital, Beaumont, Dublin D09 V2N0, Ireland

Tel +353 | 8093332

Fax +353 I 8093016

Email martinferguson@beaumont.ie
Objective: This study aims to report a case of accelerated metabolism of voriconazole in a patient with cerebral aspergillosis.

Case summary: A 36-year-old woman developed cerebral aspergillosis after immunosuppressive treatment for suspected atypical hemolytic uremic syndrome/thrombotic thrombocytopenic purpura. She was treated with voriconazole using therapeutic drug monitoring to guide dosing. After an initial high level, her dose was reduced, but over the following weeks, she required several dose increases in order to achieve a voriconazole level within the target range. The patient's dose requirements eventually stabilized at $700 \mathrm{mg}$ twice daily. Cimetidine and omeprazole were added in an effort to inhibit the metabolism of voriconazole.

Discussion: The metabolism of voriconazole is known to be highly variable among different patients depending on pharmacogenetic factors; however, an increasing rate of voriconazole metabolism in a single patient over time is not well recognized. Therapeutic drug monitoring of voriconazole in this case facilitated the use of large doses while controlling for toxicity.

Conclusion: This case is further evidence of autoinduction in voriconazole metabolism. Therapeutic drug monitoring of voriconazole is useful in detecting variation in a patient's metabolism of voriconazole over time.

Keywords: voriconazole, therapeutic drug monitoring, metabolism, enzyme inhibition, autoinduction

\section{Introduction}

Voriconazole is the first-choice antifungal treatment for cerebral aspergillosis as recommended by the Infectious Diseases Society of America guidelines. ${ }^{1}$ It has the advantage of a relatively small molecular weight, which favors its penetration across the blood-brain barrier. Other advantages include its excellent oral bioavailability and the fact that dose adjustment is not needed for renal impairment.

Disadvantages of voriconazole include significant variation among patients in their rates of metabolism of voriconazole. Cytochrome P450 (CYP)2C19 is significantly involved in the metabolism of voriconazole, and this enzyme exhibits significant genetic polymorphism. ${ }^{2}$

In this case, based on therapeutic drug monitoring, multiple dose adjustments were necessary, suggesting that the voriconazole was inducing the CYP enzymes responsible for its own metabolism. A previous report by Moriyama et $\mathrm{al}^{3}$ has suggested this phenomenon and reported that it could be partially reversed by concurrent administration of cimetidine - a well-known inhibitor of several CYP enzymes. A report on the 
autoinduction of voriconazole metabolism in a child with invasive pulmonary aspergillosis has also been published. ${ }^{4}$

\section{Case report}

A 36-year-old female Caucasian patient (weight: $83 \mathrm{~kg}$ ) presented in June 2015 with headache, general weakness, fever and features of a microangiopathic process. Cultures and serology were negative for infection, and radiology and bone marrow examination failed to demonstrate a malignancy. She deteriorated quickly, requiring respiratory and inotropic support in the intensive care unit (ICU). In view of this, she was empirically treated for atypical hemolytic uremic syndrome (aHUS)/thrombotic thrombocytopenic purpura (TTP) with high-dose steroids and plasma exchange followed by eculizumab. During the ICU stay, urine microscopy was performed and presence of hyphae was noted. Candida albicans was subsequently cultured and ocular candidiasis diagnosed. Fluconazole therapy was started. Aspergillus was subsequently cultured from a central line tip. A magnetic resonance imaging (MRI) scan of the brain showed several brain abscesses, one of which was successfully drained, and Aspergillus was identified by polymerase chain reaction.
Fluconazole was changed to voriconazole on June 29 (Day 1 of voriconazole treatment). In order to achieve therapeutic voriconazole levels within the cerebrospinal fluid, the target blood concentration of voriconazole was $3-5 \mathrm{mg} / \mathrm{L}$. Dose increases were made several times as shown in Figure 1.

An initial intravenous (IV) loading dose of $500 \mathrm{mg}$ (6 mg/ $\mathrm{kg}$ ) twice daily was given on June 29 (Day 1), followed by $320 \mathrm{mg}$ ( $4 \mathrm{mg} / \mathrm{kg}$ ) IV twice daily until the first reported trough level of $10.3 \mathrm{mg} / \mathrm{L}$ (Day 9). This high level indicated that the patient's ability to metabolize the voriconazole had been exceeded, and the dosage was reduced. After a subsequent low trough level of $0.88 \mathrm{mg} / \mathrm{L}$, the dosage was increased and changed to the oral route. Following a 48-hour period when the patient failed to receive any dose due to problems with enteral access, she was reloaded with IV voriconazole. From Day 40 to Day 110, her IV dosage requirement increased progressively to achieve a voriconazole trough level between $3 \mathrm{mg} / \mathrm{L}$ and $5 \mathrm{mg} / \mathrm{L}$ while avoiding the saturation of her metabolic capacity (Table 1). Due to the nonlinear pharmacokinetics of voriconazole, dose increases were limited to an additional $50 \mathrm{mg}$ or $100 \mathrm{mg}$ twice daily in order to avoid potentially toxic levels.

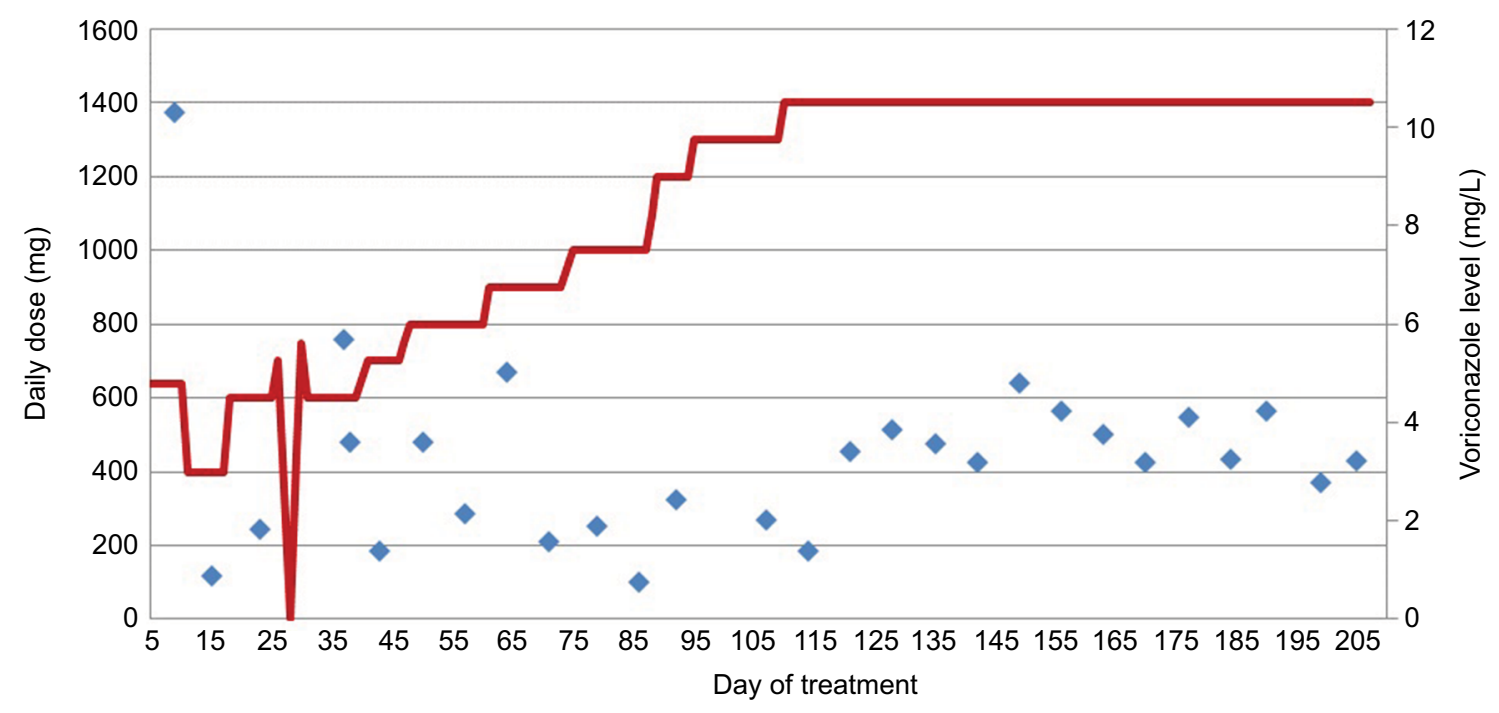

Figure I Overall pattern of an increasing total daily dose of voriconazole (red line) to maintain a safe and effective plasma level of voriconazole (blue diamonds). Note: The graph shows the variation in the total daily dose and the trough plasma level of voriconazole.

Table I Timeline of voriconazole total daily dose and route of administration

\begin{tabular}{|c|c|c|c|c|c|c|c|c|c|c|c|}
\hline Day(s) of treatment & I & $2-10$ & $11-17$ & $18-25$ & 26 & 27 & 28 & 29 & 30 & $31-39$ & \\
\hline Total daily dose, mg & 1000 & 640 & 400 & 600 & 700 & 350 & 0 & 450 & 750 & 600 & \\
\hline Route of administration & IV & IV & IV & $\mathrm{PO}$ & $\mathrm{PO}$ & $\mathrm{PO}$ & - & IV & IV & IV & \\
\hline Day(s) of treatment & 40 & $41-46$ & 47 & $48-60$ & $6 I-73$ & 74 & $75-87$ & 88 & $89-94$ & $95-109$ & $\mathrm{IIO} \rightarrow$ \\
\hline Total daily dose, mg & 650 & 700 & 750 & 800 & 900 & 950 & 1000 & 1100 & 1200 & 1300 & 1400 \\
\hline Route of administration & IV & IV & IV & IV & IV & IV & IV & IV & PO & $\mathrm{PO}$ & PO \\
\hline
\end{tabular}

Abbreviations: IV, intravenous; PO, orally. 
During her in-patient stay, the patient's weight decreased from $80 \mathrm{~kg}$ to $63 \mathrm{~kg}$, which was significant considering that the product information limits the rate of IV infusion to $3 \mathrm{mg} / \mathrm{kg} / \mathrm{h}$.

The route of administration for voriconazole was changed from IV to oral on Day 89 , and cimetidine $200 \mathrm{mg}$ twice daily orally was started in an effort to inhibit the metabolism of voriconazole by CYP enzymes. She was transferred back to her local hospital on Day 92. The cimetidine dose was increased to $400 \mathrm{mg}$ twice daily on Day 94. Additional enzyme inhibition with omeprazole was started on Day 118. Voriconazole dose requirements eventually stabilized at $700 \mathrm{mg}$ twice daily orally.

The patient was not tested for her CYP2C19 genotype status. The patient provided written consent for publication.

\section{Discussion}

Voriconazole level monitoring is not a requirement under the American or European product information for Vfend ${ }^{\circledR}$ which states that a positive association between mean, maximum or minimum plasma voriconazole concentration and efficacy in therapeutic studies was not found. ${ }^{2}$ Several studies, however, suggest a value in monitoring voriconazole levels to ensure efficacy and to avoid toxicity. ${ }^{5-7}$ The monitoring of voriconazole levels detected a significant increase in the rate of voriconazole metabolism in our patient. The use of standard maintenance doses based on the product information would, in this case, almost certainly have resulted in voriconazole levels of $<1 \mathrm{mg} / \mathrm{L}$, which has been associated with a lack of response to therapy. ${ }^{7}$ Therapeutic drug monitoring of voriconazole can allow the safe use of a much higher maintenance dose than the standard maintenance dose of $4 \mathrm{mg} / \mathrm{kg}$. Our patient eventually required a maintenance dose of $>10 \mathrm{mg} / \mathrm{kg}$ twice daily.

The addition of cimetidine in this case did not produce an immediate effect; the patient required two further voriconazole dose increases, but it is possible that the combination of cimetidine and omeprazole as enzyme inhibitors helped to stabilize the patient's dose requirements. The patient was not on any medicines that are associated with an increase in voriconazole metabolism.

\section{Conclusion}

Our patient's voriconazole dose requirements increased over time in a manner that suggested that voriconazole was inducing the enzymes responsible for its own metabolism. Dose adjustment was complicated by the nonlinear pharmacokinetics of voriconazole, but the patient's dose requirements eventually stabilized at $700 \mathrm{mg}$ twice daily orally, possibly due to the effects of the concurrently administered enzyme inhibitors.

\section{Disclosure}

The authors report no conflicts of interest in this work.

\section{References}

1. Walsh TJ, Anaissie EJ, Denning DW, et al; Infectious Diseases Society of America. Treatment of aspergillosis: clinical practice guidelines of the Infectious Diseases Society of America. Clin Infect Dis. 2008;46(3): $327-360$.

2. Vfend ${ }^{\circledR}$ (voriconazole) infusion [package insert]. New York, NY: Pfizer Inc; 2010.

3. Moriyama B, Elinoff J, Danner RL, et al. Accelerated metabolism of voriconazole and its partial reversal by cimetidine. Antimicrob Agents Chemother. 2009;53(4):1712-1714.

4. Hsu AJ, Dabb A, Arav-Boger R. Autoinduction of voriconazole metabolism in a child with invasive pulmonary aspergillosis. Pharmacotherapy. 2015;35(4):e20-e26.

5. Smith J, Safdar N, Knasinski V, et al. Voriconazole therapeutic drug monitoring. Antimicrob Agents Chemother. 2006;50(4):1570-1572.

6. Miyakis S, van Hal SJ, Ray J, Marriott D. Voriconazole concentrations and outcome of invasive fungal infections. Clin Microbiol Infect. 2010;16(7):927-933.

7. Pascual A, Calandra T, Bolay S, Buclin T, Bille J, Marchetti O. Voriconazole therapeutic drug monitoring in patients with invasive mycoses improves efficacy and safety outcomes. Clin Infect Dis. 2008;46(2):201-211.
Drug, Healthcare and Patient Safety

\section{Publish your work in this journal}

Drug, Healthcare and Patient Safety is an international, peer-reviewed open access journal exploring patient safety issues in the healthcare continuum from diagnostic and screening interventions through to treatment, drug therapy and surgery. The journal is characterized by the rapid reporting of reviews, original research, clinical, epidemiological and

\section{Dovepress}

post-marketing surveillance studies, risk management, health literacy and educational programs across all areas of healthcare delivery. The manuscript management system is completely online and includes a very quick and fair peer-review system. Visit http://www.dovepress.com/ testimonials.php to read real quotes from published authors. 